\title{
Developing Strategies to Improve Advance Care Planning in Long Term Care Homes: Giving Voice to Residents and Their Family Members
}

\author{
Kimberly Ramsbottom ${ }^{1}$ and Mary Lou Kelley ${ }^{2}$ \\ ${ }^{1}$ Centre for Education and Research on Aging and Health, Lakehead University, 955 Oliver Road, \\ Thunder Bay, ON, Canada P7B 5E1 \\ ${ }^{2}$ School of Social Work and Northern Ontario School of Medicine, Lakehead University, 955 Oliver Road, \\ Thunder Bay, ON, Canada P7B 5E1
}

Correspondence should be addressed to Mary Lou Kelley; mlkelley@lakeheadu.ca

Received 30 November 2013; Revised 10 March 2014; Accepted 16 March 2014; Published 14 April 2014

Academic Editor: Phillip J. Newton

Copyright (C) 2014 K. Ramsbottom and M. L. Kelley. This is an open access article distributed under the Creative Commons Attribution License, which permits unrestricted use, distribution, and reproduction in any medium, provided the original work is properly cited.

\begin{abstract}
Long term care (LTC) homes, also known as residential care homes, commonly care for residents until death, making palliative care and advance care planning (ACP) important elements of care. However, limited research exists on ACP in LTC. In particular, research giving voice to family members and substitute decision makers is lacking. The objective of this research was to understand experiences, perspectives, and preferences to guide quality improvement of ACP in LTC. This qualitative descriptive study conducted 34 individual semistructured interviews in two LTC homes, located in Canada. The participants were 31 family members and three staff, consisting of a front line care worker, a registered nurse, and a nurse practitioner. All participants perceived ACP conversations as valuable to provide "resident-centred care"; however, none of the participants had a good understanding of ACP, limiting its effectiveness. Strategies generated through the research to improve ACP were as follows: educating families and staff on ACP and end-of-life care options; better preparing staff for ACP conversations; providing staff skills training and guidelines; and LTC staff initiating systematic, proactive conversations using careful timing. These strategies can guide quality improvement of palliative care and development of ACP tools and resources specific to the LTC home sector.
\end{abstract}

\section{Introduction}

Long term care (LTC) homes today provide care to people of advanced age, frailty, or disability, with multiple health problems $[1,2]$. Increasingly, they provide end-of-life care [3$5]$ as approximately one in five residents living in LTC homes in Canada and UK dies each year [6-9]. Yet, there exists a culture of silence surrounding dying that creates a barrier to end-of-life communications in LTC $[2,10]$. Lack of discussion with the resident and the resident's substitute decision-maker, most commonly a family member, about end-of-life wishes can lead to unnecessary and unwanted medical treatments $[11,12]$, unnecessary transfers to the acute hospital [13], and discomfort and anxiety for both the resident and family [14]. Implementing effective advance care planning (ACP) can improve patient and family satisfaction with care and increase the likelihood that people will die in their setting of choice $[12,15]$. Dying at home in the long term care home can be offered as an option during ACP discussions.

ACP is a structured conversation to help people decide, communicate, and document their wishes for care at the end of life $[16,17]$. ACP is viewed as an essential component of a quality palliative care program and provides LTC residents important decision-making opportunities [18-20] that can guide their caregivers when they cannot speak for themselves [21-23]. Knowing individuals' preferences for care and enabling them to die where they choose are recognized as the gold standard in palliative care [11]. Having comprehensive up to date advance care plans can help staff create a peaceful 
environment for dying residents and their families within LTC [24] and avoid unnecessary health care expenditures [14].

Good end-of-life (EOL) decision-making is a prerequisite for quality EOL care $[25,26]$. It is thus imperative that health care providers in LTC proactively have conversations with family members and prepare them for the death of their loved one. It is the trusting relationship between health care provider, resident, and family members that can generate the ACP discussion and enable a "good death" for residents. Family and friends who are forewarned or prepared for the death are better able to prepare psychologically; a frequent source of frustration for families is that health care providers never discussed the fact that their loved one was dying [27]. Effective ACP can reduce stress, anxiety, and depression in surviving relatives [12].

While there has been considerable research done about ACP in hospitals [28], specific knowledge about implementing ACP in the LTC sector is inadequate [29]. Existing LTC data suggest that policies and procedures related to ACP are limited and the quality of the existing ACP documentation is poor [30]. The perspectives of LTC residents, their families, and substitute decision-makers are particularly lacking to guide ACP quality improvement strategies [31], thus making it a priority to explore what is most important to them in EOL decision-making [32]. We specifically need to understand when, how, and who should have ACP conversations in LTC.

International literature and research support ACP as an essential component for providing quality palliative care in LTC settings. To date, research from Europe, Australia, and the United States indicates the following essential guidelines for long term care and residential care homes: the importance of documenting ACP conversations; the importance of education on palliative care and advance care planning; sharing information across multidisciplines within the home; ACP is an ongoing process and conversations need to be revisited; and health care providers need to initiate the conversation [33-37].

However, little is known about the views of residents, families, and staff members on ACP in LTC homes [38]. International literature suggests the ACP in long term care/ residential care homes is imperative to providing palliative care and should be conducted early after admission [35]. Nonetheless, minimal research has been done to date on ACP in LTC homes that focuses on strategies, guidelines, policy, and procedures for implementation of ACP conversations. ACP in residential home setting has existed as an idea for many years; however, approval and operationalization of ACP in routine practice have been minimal, despite the confirmation of its benefits [37]. This research explores these issues in a Canadian context but seeks to move beyond problem identification to creating specific strategies that incorporate the perspectives of those who actually need to engage in these conversations: family members, most who act as substitute decision-makers, and LTC staff who interact with residents and families on a day to day basis. To this end, a qualitative study with residents' family members/substitute decisionmakers and nursing staff of LTC homes was conducted, with the purpose of exploring their ACP experiences, perspectives, and preferences to guide quality improvement initiatives and create resources for LTC homes. This research was a substudy of a five-year project "Improving Quality of Life for People Dying in Long Term Care Homes (2009-2013)," also known as "Quality Palliative Care in Long Term Care (QPC-LTC) Alliance," that has developed a framework and toolkit for implementing quality palliative care programs in LTC homes [39].

As part of the initial data collection for the above mentioned five-year research project, a "Family Member Interview Guide" was created by the research team, and interviews were conducted with 23 family members of residents living within two Ontario LTC homes during 2010. The interview guide of 33 questions explored participants' experiences and perceptions of residents' quality of life in the respective homes with a focus on palliative and end-of-life care and advance care planning, including the following questions: what is your understanding of palliative care? When should conversations about palliative care happen with family members? Who should inform family members about their loved one's change in status to palliative care? Has anyone (in the LTC home) ever talked to you about palliative care? Has anyone in the LTC home talked to you about completing an advanced care plan?

All interviews were between 30 and 60 minutes and were conducted by the QPC-LTC research staff, at a location chosen by the family member. The interviews were recorded and transcribed verbatim, and content analysis was conducted independently by two research assistants to identify themes and achieve consensus related to families' experience and perceptions of palliative care and ACP. The results of this analysis revealed that families lacked understanding of palliative care but strongly emphasized the importance of ACP discussions occurring in LTC homes. Most families recalled completing a medical directive with a registered nurse at the time of admission; however, these conversations covered only medical issues that may be experienced and did not include discussing palliative care offered in the LTC home or the resident's social, psychological, and spiritual wishes regarding end-of-life care. The focus was on whether the resident should be transferred to hospital to die. Families also expressed that very little information or education about ACP was given to them during the time of this discussion.

The results from this initial data collection identified that in participating LTC homes there were minimal understanding and communication of ACP, with no formalized and systematic process for discussion beyond medical directives. Yet, data show that participants felt the ACP discussions were beneficial and needed. Similar to the findings in international literature, our research has shown the benefits of ACP, yet highlighted the need for a systematic process to initiate these conversations from a family or staff perspective. Thus, to build upon the findings of the initial data collection, the QPC-LTC Alliance conducted a second substudy to identify the specific family's and staff members' perceptions of the strategies that could be used to enhance ACP in LTC homes. It is hoped that the findings of this substudy will fill a gap in the literature and can inform development of ACP strategies and resources for LTC settings. 
TABLE 1: Interview domains and sample questions for family members.

\begin{tabular}{ll}
\hline Interview domains & Sample questions \\
\hline Perceptions of ACP & (i) What is your understanding of advance care planning? Do you see it as a valuable process? \\
& $\begin{array}{l}\text { (ii) Have you and [resident's name] ever had conversations about his/her wishes surrounding } \\
\text { end-of-life care? If yes, can you describe how and when these discussions occurred? }\end{array}$ \\
\hline Resident care wishes & $\begin{array}{l}\text { (i) What would be his/her wishes for medical, social, psychological, and spiritual support at the } \\
\text { end of life? } \\
\text { (ii) What do you think LTC staff should know about [your resident] to best provide his/her care at } \\
\text { the end of life? }\end{array}$ \\
\hline Beginning conversations & (i) When do you think care planning, related to end-of-life issues, should begin? \\
\hline & (ii) Who should initiate these conversations? \\
Implementing ACP & (i) How would you like to be involved in [resident's] care planning for end-of-life care? \\
(ii) How can the LTC home encourage residents and families to get involved in advanced care \\
planning?
\end{tabular}

\section{Methods}

2.1. Design. This descriptive research used a qualitative approach to understand the experiences, perspectives, and preferences of residents' family members and LTC staff on implementing ACP in their long term care/residential care homes. The study was done in two 100-bed LTC homes in Thunder Bay, Ontario, Canada, in 2012.

2.2. Sampling and Recruitment. Purposeful sampling methods were used to obtain 11 participants who were either family members of residents living in one of the LTC homes or staff working in these homes. Family members who were involved with a resident and visited frequently were viewed to be good and potential participants. These individuals were identified by the LTC home manager and invited to participate by the research project manager either in person or by letter. Eight family members volunteered to be interviewed, including seven daughters and one husband, with seven out of eight being substitute decision-makers for a resident. The staff participants included a personal support worker, a registered nurse, and a nurse practitioner working in the LTC home who were recruited by the project manager. Ethical approval was received from Lakehead University and St. Joseph's Care Group, Thunder Bay, Ontario.

2.3. Data Collection. Each participant was contacted by a research assistant to confirm their willingness to participate and establish a time convenient for the participant to meet. Informed consent was obtained and all research and ethics procedures were followed. The interviews, conducted in person, took place at two LTC homes, with the average length of 45 minutes. Each interview was audio-recorded from start to finish.

The interviews were semistructured, with open ended questions specifically developed for this project. The questions, illustrated in Tables 1 and 2, were developed through an extensive literature examination and by reviewing results of an environmental assessment of palliative care knowledge, values, and current practices (2009) that was conducted in these two LTC settings as part of the larger QPC-LTC study. These data identified lack of understanding of ACP on the part of staff and residents, staff discomfort with having APC discussions, and inconsistent implementation of ACP within the organization.

2.4. Analysis. The audio taped interviews were transcribed verbatim by the research assistant who conducted the interview. To meet the goal of the research, the analysis explored knowledge, experience, current practices, concerns, priorities, and workable strategies that would facilitate the development of ACP processes in the LTC settings. The analysis used an inductive analytic approach and a three-level process of coding, theming, and interpretive description [40]. All levels of coding were reviewed by the principal researcher and seven research assistants who met weekly to achieve consensus and ensure rigor when analysing the data. Saturation occurred when commonalities aroused from thematic analysis of the data. Evidence from the data that support and illustrate the themes was identified, using verbatim quotes taken directly from the transcribed audio files.

\section{Results}

Family members and staff perceived ACP conversations as valuable to provide "resident-centred care"; however, neither had a good understanding of ACP, limiting its effectiveness. Staff found having ACP conversations difficult and lacked skills and knowledge of care options. Four common themes that emerged from the interviews were (1) the need for education; (2) preparation for ACP conversations; (3) facilitation of ACP conversations; and (4) appropriate timing of initiating ACP conversations (see Table 3). These themes, described in detail below and separated into family members' perceptions and staff's strategies, offer approaches to guide quality improvement of palliative care in LTC and specifically development of ACP tools and resources.

3.1. Family Perceptions of Implementing ACP into LTC Homes. The family members/substitute decision-makers felt that the LTC homes should proactively and consistently provide information and education to staff and family members on ACP. Suggestions included providing more information for residents and families during interviews/meetings at 
TABLE 2: Interview domains and sample questions for LTC staff.

\begin{tabular}{ll}
\hline Interview domains & Sample questions \\
\hline Perceptions of ACP & (i) What is the difference between advance care planning and care planning? \\
& (ii) How does advance care plan support you in providing resident-centered care \\
\hline (i) What qualities and skills are required to initiate and carry out a conversation regarding advance \\
care planning? \\
(ii) How do you initiate advance care planning conversations? \\
(a) Location? \\
(b) Certain phrases or wording? \\
(c) Timing? \\
(d) Who do you include in the conversation? \\
(e) With a reluctant resident or family member? \\
Implementing ACP & (i) What are key facilitators or barriers to doing care planning in long term care homes? \\
& (ii) Would it be helpful to have documentation guidelines to assist us in creating guidelines for care \\
planning? If so, what would you suggest?
\end{tabular}

TABLE 3: Common family and staff strategies/priorities in implementing ACP conversations in LTC homes.

\begin{tabular}{|c|c|c|c|}
\hline Strategies & Key process & Who & Recommendations \\
\hline $\begin{array}{l}\text { Understanding } \\
\text { ACP }\end{array}$ & $\begin{array}{l}\text { Knowing } \\
\text { importance of } \\
\text { having ACP } \\
\text { conversations }\end{array}$ & $\begin{array}{l}\text { Family members, } \\
\text { substitute decision } \\
\text { makers, and staff }\end{array}$ & $\begin{array}{l}\text { Educate residents, family members, and staff on care } \\
\text { options and palliative care services }\end{array}$ \\
\hline $\begin{array}{l}\text { Preparing for ACP } \\
\text { conversations }\end{array}$ & $\begin{array}{l}\text { Knowing the } \\
\text { resident well, } \\
\text { holistically }\end{array}$ & Staff & $\begin{array}{l}\text { (i) Know residents' social history } \\
\text { (ii) All staff should be involved in ACP } \\
\text { (iii) Emotional, physical, social, and spiritual care needs } \\
\text { are all identified }\end{array}$ \\
\hline $\begin{array}{l}\text { Facilitating ACP } \\
\text { conversations }\end{array}$ & $\begin{array}{l}\text { Knowing how to } \\
\text { have conversation }\end{array}$ & Staff & $\begin{array}{l}\text { (i) Create guidelines and resources to assist staff } \\
\text { (ii) Training for skills to initiate conversations } \\
\text { (iii) Creating time/patience for ongoing conversations }\end{array}$ \\
\hline $\begin{array}{l}\text { Timing ACP } \\
\text { conversations }\end{array}$ & $\begin{array}{l}\text { Knowing when ACP } \\
\text { conversations } \\
\text { should be initiated }\end{array}$ & Staff & $\begin{array}{l}\text { (i) Give information prior to admission to LTC } \\
\text { (ii) Initiate ACP meeting 6-8 weeks after admission } \\
\text { (iii) Continue communication throughout stay in LTC }\end{array}$ \\
\hline
\end{tabular}

the time of application and with all regular informational mail-out flyers about ACP and LTC homes. The need was also expressed for external educational supports regarding the meaning of ACP, such as community workshops, media information, community health fairs, conferences, and community presentations. The importance of information to families is illustrated in the following quote:

...getting the right information...and enough information to help, you know, develop a meaningful plan of care...because the plan of care is, is the residents' book of this is who I am... this is how I want to be cared for... and these are my goals. (family member)

Family members also felt that LTC staff lack knowledge on "how" to initiate and execute ACP conversations with residents and family members. It was perceived that staff need to be better educated on what care options and services were available in order to better inform and guide family members or residents. Family members also stated the staff would benefit from education on how to approach families and when the appropriate time to do so is. The following quote illustrates a family member's concern about timing:
I wish they wouldn't do it while my father is sitting in the room because it would be, you know, very uncomfortable doing the DNR, he gets upset every time that topic has come up. So sometimes I think they should be more careful when they have that discussion with the decision maker. (family member)

The family members acknowledged they need more education regarding care options in order to participate in ACP conversations, specifically with regards to palliative care and EOL care services available in the LTC home. This lack of knowledge could lead to avoidable hospitalization as illustrated below:

$$
\begin{aligned}
& \text {...cause I did not realize... I just did not know the } \\
& \text { system...because people do not know what it's like. } \\
& \text { So when you are asked for that decision, you are } \\
& \text { thinking the hospital is the best place... I did not } \\
& \text { realize they do everything here that they do in the } \\
& \text { hospital. (family member) }
\end{aligned}
$$

Family members felt it would be helpful if staff knew the residents' personal/social history prior to initiating the conversations. One participant stated the following: 
I think...staff should really know the person as a person, [as the resident was] before coming into long term care...capturing the past into the present, I think it's important.

Knowing the resident well can create a comfortable environment which could facilitate ACP dialogue that is "individualized" to meet the wishes of the resident. The knowledge of resident's history could also assist staff when discussing his/her wishes for physical, social, spiritual, and psychological care needs.

All study participants stated it is vital for LTC staff to communicate with a resident and their family members about wishes, beliefs, and values in order to provide the best possible care to a resident. Family members felt that only with continuous communication, beyond formal ACP meetings, could the resident's EOL care wishes be fulfilled. They felt staff need to be aware of all resident's values and preferences, not only medical wishes, in order to provide "resident-centered care." The diversity amongst residents' spiritual preferences at EOL is illustrated below.

...I've discussed this, her spiritual needs, I mean she was a very faithful person when she was well, but... I think that would still be important at end of life. (family member)

...no invasion into her, I would say spirituality, which has always been very personal with Mom like no church has ever been involved. . she would be quite upset if a priest or somebody was brought it. (family member)

3.2. Staff Strategies for Implementing ACP into LTC Homes. The participating staff themselves felt that all staff involved in direct care of a resident should be aware of any ACP conversations that have taken place since all staff involvement can help to ensure that a resident's care needs are being met in a holistic manner. The need to include the entire LTC team is emphasized below.

The physician, spiritual care, life enrichment, it's
trying to include all the members of the team so
that everybody is aware of what conversations
have taken place but understanding of the infor-
mation too. (staff member)

All staff participants stated that having guidelines about facilitating conversations would promote consistency of ACP dialogue. The guidelines should encompass residents' holistic care needs-physical, social, spiritual, and emotional-and not be limited to medical directives. Guidelines could also ensure that ACP conversation would be consistent. The quotes below illustrate this point.

Any kind of guidelines, documentation guidelines is important for clarity, what should be covered, what needs to be covered, as well as for consistency because of the individual variables with everything. (staff member)
Consistency is a big thing because there's so much variables in the way you or I do things, I'm not saying there's anything wrong with that, it's just certain things need to be covered and guidelines are a helpful way to ensure some things do not get missed.

The participants identified that staff who are going to initiate the ACP talk should first assess whether residents or family members are ready to have these conversations. Talking in comfortable private environments can insure open communication. One staff stated the following:

Staff guidelines; again, be supportive and understanding of the social, cultural, spiritual and physical needs of the resident and within all those contexts for that person.

The participants also stressed the importance of being empathetic and patient, taking time when engaging in ACP conversations. These humanistic qualities and approaches were elaborated below.

\section{Compassion, patience, ability to keep it [conversa- tion] on track, and to know when they have had enough and you have to back away. (staff)}

Empathy and support, of course, to the family as this is their loved one. (staff)

To successfully initiate ACP conversations, all participants suggested similar phrases or questions staff could use with residents and their family members. Some suggested examples of how to start these conversations are listed in Table 4.

Staff noted that, after having any discussion with residents or family members, it is essential to document the details of the ACP conversations that took place since, "If it's [ACP conversations] verbal and it's not documented, then it did not happen" (staff). The importance of documenting any subtle changes in resident's condition was also identified. Important conversations about care wishes often occur between residents, families, and nonregistered care staff, for example, personal support workers, care aides, or housekeepers. These also need to be confirmed and documented. The documentation can create a consistent message of care needs across the disciplines working in LTC, thus reducing questions and ensuring the resident care needs are met.

Staff participants felt that ACP conversations need to take place as soon as possible after admission; however, they acknowledged that residents and families are overwhelmed on the admission day. Therefore, there should be a separate meeting initiated by the LTC staff about six to eight weeks after admission to specifically discuss ACP. The meeting is planned at admission, and a pamphlet of ACP information is given to review in preparation. Further, future residents of the home should be given more detailed ACP information prior to entering the LTC home.

Personally I think [ACP] should be done long before they [residents] come into the home, when 
TABLE 4: Suggested questions/phrases to help start conversations about ACP with residents and family members.

\begin{abstract}
Questions/phrases for residents
(1) "Have you thought about what you would like in the last phase of your life or what would be the most important for you during that time?"

(2) "There is a change we are seeing and we need to have these conversations so we are clear that we are all on the same page as to what treatment direction we will be taking."
\end{abstract}

(3) "We need to talk about the treatment direction and goals."
Questions/phrases for family members/substitute decision makers

(1) "We noticed that your mom's condition is slowly deteriorating/acutely deteriorating [or whatever the case may be...]"

(2) "There is a change we are seeing and we need to have these conversations so we are clear that we are all on the same page as to what treatment direction we will be taking."

(3) "We need to talk about the treatment direction and goals."

(4) "Has your mom or dad ever talked to you about what their wishes have been?"

(5) "What is in the best interest of the resident. ..." they receive the application to come into the home and it should be done then when they are able to think about it. (staff)

Staff participants also discussed the relevance of continued communication between staff, residents, and family members to alleviate potentially stressful emergency decision-making. One participant articulated that they "...need to ensure constant communication in regard to treatment plan with any change in condition, and being on top of those changes as well as consistently to avoid crisis situations." (staff)

\section{Discussion}

This research, conducted as part of the QPC-LTC research project, has affirmed that family members' understanding of ACP in LTC homes is limited. Without systematic processes in place for ACP, family members are left unsure of what resources, care options, and services are available to their loved ones at end of life. Resident's wishes, values, and beliefs cannot be known if ongoing communication is not taking place, and there is no documentation of their wishes.

Differentiating between ACP and care planning for daily care is often puzzling to staff in LTC homes. Confusion about the difference between them creates a barrier to initiating ACP conversations, compounded by the general discomfort staff have with EOL conversations. All study participants shared a common feeling of not having a clear understanding of the differences between ACP and the general plan of care. All participants, however, agreed about the importance of ACP as part of EOL communication.

ACP, the process of looking ahead and discussing future care wishes at the end of life, is separate from the elements of the care plan to meet residents' daily current needs. Data suggest that ACP discussions should be proactively initiated by LTC staff early in the stay of each resident, although not at admission, and again whenever a resident has a significant change in status that could signify transitioning towards end of life. As the clinical and emotional needs of a resident change, the daily care plan can evolve and incorporate the known wishes, enabling the interdisciplinary care team to deliver individualized, holistic care to residents [41]. Future wishes, documented or verbal, require affirmation from residents or substitute decision-makers through the normal legal processes of health care consent before being incorporated into the care plan.

Knowing the social history of the resident well, and providing a clear and concise understanding of the care options available to the resident, is essential for staff who are preparing to initiate ACP conversations. This preparation will guide the residents and substitute decision-makers when having to make informed decisions. Documentation of all conversations with residents, staff, and family members/substitute decision-makers is also crucial to this process. A clear and concise record of conversations can help ensure that all involved caregivers have a common understanding. Any significant change of status in a resident's condition signals a need to initiate ACP conversations.

The study has also shown that family members are open to have ACP discussions; however, they are more comfortable when staff initiate the conversations. Families look to staff to guide the ACP process and assess timing and their readiness. By implementing effective ACP processes, LTC can help create a culture where death is a comfortable topic of discussion. By having open and caring dialogue regarding ACP, LTC homes can move towards providing higher quality palliative care to all residents.

Certain limitations to this study are recognized. This was a small qualitative study, with data collected in Canada, and therefore the applicability of the findings beyond the study population will need to be validated in the future. However, the consistency in findings of other existing research on the needs and problems of ACP in LTC from England, Australia, and the United States suggests the potential applicability of our findings more broadly than Canada, especially with a contribution regarding the family members' perspectives. We encourage our international colleagues to replicate this study in their home environment. 


\section{Conclusion}

This research identified four key processes crucial to implementing effective ACP conversations in LTC homes: education, preparation, facilitation, and timing of ACP conversations. Some practical strategies have emerged from the data: (1) education for residents, families, and staff on ACP and end-of-life care options prior to admission and on an ongoing basis afterwards; (2) better prepared staff to initiate ACP conversations by knowing the resident's history well; (3) providing staff with ACP skills training and guidelines; and (4) developing organizational processes for systematic and proactive initiation of ACP conversations with families and residents, giving attention to careful timing. These strategies can guide quality improvement of palliative care in LTC, specifically the development of ACP tools and resources.

Subtle differences were observed between family members and staff regarding the implementation of ACP conversations. Family members expressed a need for more information about ACP during interviews and meetings at the time of application process. They also felt their knowledge on how to initiate the ACP conversations is lacking, and thus staff should be the initiator. They expressed a need for more education regarding the available care options for their loved ones. Family members also believed that ongoing communication with staff regarding the resident's values and preferences is very important.

Staff members felt that ACP conversation should take place as soon as possible after admission. Also, everyone needs to be aware of any ongoing ACP conversations that took place. Developing guidelines on how to facilitate ACP conversations, and continued communication between staff, residents, and family members, would promote the consistency of ACP dialogue throughout the LTC home.

The key element to ACP is communication, especially hearing the voices of residents and their family members about their EOL care wishes. Lack of understanding of ACP, lack of knowledge of care options and services, lack of skill and time for facilitating conversations, and health care providers' discomfort discussing EOL issues can impede these important conversations from happening. By focusing on the strategies identified through this research and creating resources to educate staff, families, and residents, LTC homes could implement a more systematic approach to ACP and better meet resident and family's end-of-life care wishes.

\section{Conflict of Interests}

The authors declare that there is no conflict of interests regarding the publication of this paper.

\section{Acknowledgments}

This research was supported by the Canadian Social Sciences and Humanities Research Council (SSHRC) and Canadian Institutes of Health Research (CIHR FRN: 112484). The authors' thanks go to their study participants, their partner St. Joseph's Care Group in Thunder Bay, ON, and especially Valerie Jenson, Jackie MacDonald and Mary Jane Melita, and the graduate student research assistants Leonard Bohler, Ashley Clarkson, Scott Fredin, Kate Nicol, Stacey Saukko, and Kristie Williamson.

\section{References}

[1] S. Aylward, P. Stolee, N. Keat, and V. Johncox, "Effectiveness of continuing education in long-term care: a literature review," Gerontologist, vol. 43, no. 2, pp. 259-271, 2003.

[2] J. Österlind, G. Hansebo, J. Andersson, B.-M. Ternestedt, and I. Hellström, "A discourse of silence: professional carers reasoning about death and dying in nursing homes," Ageing and Society, vol. 31, pp. 529-544, 2011.

[3] K. Brazil, P. Krueger, M. Bedard et al., "Quality of care for residents dying in Ontario long-term care facilities: findings from a survey of directors of care," Journal of Palliative Care, vol. 22, no. 1, pp. 18-25, 2006.

[4] S. M. Wowchuk, S. McClement, and J. Bond Jr., "The challenge of providing palliative care in the nursing home-part 1 . External factors," International Journal of Palliative Nursing, vol. 12, no. 6, pp. 260-267, 2006.

[5] J. P. Hirdes, L. Mitchell, C. J. Maxwell, and N. White, "Beyond the "iron lungs of gerontology": using evidence to shape the future of nursing homes in Canada," Canadian Journal on Aging, vol. 30, no. 3, pp. 371-390, 2011.

[6] Statistics Canada: Residential care facilities, 2009-2010, http:// www5.statcan.gc.ca/access_acces/alternative_alternatif.action? teng $=83-237-x 2012001-e n g . p d f \& t f r a=83-237-x 2012001-$ fra.pdf\& $\mathrm{l}=$ eng\&loc $=83-237-\mathrm{x} 2012001$-eng.pdf.

[7] S. S. Travis, M. Bernard, S. Dixon, W. J. McAuley, G. Loving, and L. McClanahan, "Obstacles to palliation and end-of-life care in a long-term care facility," Gerontologist, vol. 42, no. 3, pp. 342349, 2002.

[8] Canadian Institute for Health Information: Continuing care reporting system (CCRS), Quick Stats Tables 2011-2012, CIHI, Canada, Ottawa, 2012.

[9] F. Stewart, C. Goddard, R. Schiff, and S. Hall, "Advanced care planning in care homes for older people: a qualitative study of the views of care staff and families," Age and Ageing, vol. 40, no. 3, pp. 330-335, 2011.

[10] D. P. Oliver, D. Porock, and D. B. Oliver, "Managing the secrets of dying backstage: the voices of nursing home staff," Omega, vol. 53, no. 3, pp. 193-207, 2006.

[11] F. Badger, C. Clifford, A. Hewison, and K. Thomas, "An evaluation of the implementation of a programme to improve end-of-life care in nursing homes," Palliative Medicine, vol. 23, no. 6, pp. 502-511, 2009.

[12] K. M. Detering, A. D. Hancock, M. C. Reade, and W. Silvester, "The impact of advance care planning on end of life care in elderly patients: randomised controlled trial," British Medical Journal, vol. 340, Article ID c1345, 2010.

[13] L. Ceronsky and D. E. Weissman, "Helping families in longterm care facing complex decisions: applying the evidence about family meetings from other settings," Annals of Long-Term Care, vol. 19, no. 2, pp. 27-32, 2011.

[14] J. G. Ouslander, M. Perloe, J. H. Givens, L. Kluge, T. Rutland, and G. Lamb, "Reducing potentially avoidable hospitalizations of nursing home residents: results of a pilot quality improvement project," Journal of the American Medical Directors Association, vol. 10, no. 9, pp. 644-652, 2009. 
[15] A. A. Wright, B. Zhang, A. Ray et al., "Associations between end-of-life discussions, patient mental health, medical care near death, and caregiver bereavement adjustment," Journal of the American Medical Association, vol. 300, no. 14, pp. 1665-1673, 2008.

[16] L. Robinson, C. Dickinson, N. Rousseau et al., "A systematic review of the effectiveness of advance care planning interventions for people with cognitive impairment and dementia," Age and Ageing, vol. 41, no. 2, pp. 263-269, 2012.

[17] Speak Up, "Start the conversation about end-of-life care," 2013, http://www.advancecareplanning.ca.

[18] W. J. McAuley, R. J. Buchanan, S. S. Travis, S. Wang, and M. Kim, "Recent trends in advance directives at nursing home admission and one year after admission," Gerontologist, vol. 46, no. 3, pp. 377-381, 2006.

[19] J. Blackford, E. Strickland, and B. Morris, "Advance care planning in residential aged care facilities," Contemporary Nurse, vol. 27, no. 1, pp. 141-151, 2007.

[20] L. H. Mallery and P. Moorhouse, "Respecting frailty," Journal of Medical Ethics, 2010.

[21] Canadian Hospice Palliative Care Association, "Advance care planning," 2013, http://www.chpca.net/.

[22] S. D. Ramsaroop, M. C. Reid, and R. D. Adelman, "Completing an advance directive in the primary care setting: what do we need for success?" Journal of the American Geriatrics Society, vol. 55, no. 2, pp. 277-283, 2007.

[23] M. D. Cantor and R. A. Pearlman, "Advance care planning in long-term care facilities," Journal of the American Medical Directors Association, vol. 4, no. 2, pp. 101-107, 2003.

[24] P. Triplett, B. S. Black, H. Phillips et al., "Content of advance directives for individuals with advanced dementia," Journal of Aging and Health, vol. 20, no. 5, pp. 583-596, 2008.

[25] H. C. Lambert, M. A. McColl, J. Gilbert, J. Wong, G. Murray, and S. E. D. Shortt, "Factors affecting long-term-care residents' decision-making processes as they formulate advance directives," Gerontologist, vol. 45, no. 5, pp. 626-633, 2005.

[26] J. Watson, J. Hockley, and S. Murray, "Evaluating effectiveness of the GSFCH and LCP in care homes," End of Life Care, vol. 4, pp. 42-49, 2010.

[27] R. S. Hebert, H. G. Prigerson, R. Schulz, and R. M. Arnold, "Preparing caregivers for the death of a loved one: a theoretical framework and suggestions for future research," Journal of Palliative Medicine, vol. 9, no. 5, pp. 1164-1171, 2006.

[28] J. Simon, P. Porterfield, S. Raffin Bouchal, and D. Heyland, “Not yet' and "just ask": barrieres and facilitators to advance care planning-a qualitative descriptive study of the perspectives of seriously ill, older patienrs and their families," BMJ Supportive \& Palliative Care, 2013.

[29] S. Y.-S. Jeong, I. Higgins, and M. McMillan, "The essentials of advance care planning for end-of-life care for older people," Journal of Clinical Nursing, vol. 19, no. 3-4, pp. 389-397, 2010.

[30] W. Silvester, R. S. Fullman, and R. A. Parslow, "Quality of advance care planning policy and practice in residential aged care facilities in Australia," BMJ Support Palliat Care, vol. 3, pp. 349-357, 2012.

[31] D. K. Heyland, P. Dodek, G. Rocker et al., "What matters most in end-of-life care: perceptions of seriously ill patients and their family members," Canadian Medical Association Journal, vol. 174, no. 5, pp. 627-633, 2006.
[32] D. B. Bekelman, C. T. Nowels, J. H. Retrum et al., "Giving voice to patients' and family caregivers' needs in chronic heart failure: implications for palliative care programs," Journal of Palliative Medicine, vol. 14, no. 12, pp. 1317-1324, 2011.

[33] J. L. Phillips, P. M. Davidson, R. Ollerton, D. Jackson, and L. Kristjanson, "A survey of commitment and compassion among nurses in residential aged care," International Journal of Palliative Nursing, vol. 13, no. 6, pp. 282-290, 2007.

[34] J. Phillips, P. M. Davidson, D. Jackson, L. Kristjanson, J. Daly, and J. Curran, "Residential aged care: the last frontier for palliative care," Journal of Advanced Nursing, vol. 55, no. 4, pp. 416-424, 2006.

[35] E. Sherwen, "How to use advance care planning in a care home," Art \& Science, vol. 25, pp. 14-18, 2013.

[36] J. J. Rhee, N. A. Zwar, and L. A. Kemp, "How is advance care planning conceptualised in Australia? Findings from key informant interviews," Australian Health Review, vol. 35, no. 2, pp. 197-203, 2011.

[37] J. Kwak, E. Ko, and B. J. Kramer, "Facilitating advance care planning with ethnically diverse groups of frail, low-income elders in the USA: perspectives of care managers on challenges and recommendations," Health \& Social Care in the Community, vol. 22, pp. 169-177, 2014.

[38] I. A. Scott, G. K. Mitchell, E. J. Reymond, and M. P. Daly, "Difficult but necessary conversations-the case for advance care planning," Medical Journal of Australia, vol. 199, pp. 662666, 2013.

[39] "Quality Palliative Care in Long Term Care. A CommunityUniversity Research Alliance," 2013, http://www.palliativealliance.ca.

[40] S. Thorne, S. Reimer Kirkham, and K. O’Flynn-Magee, “The analytic Challenge in interpretive description," International Journal of Qualitative Methods, vol. 3, pp. 1-21, 2004.

[41] M. L. Matzo and D. W. Sherman, "Palliative care nursing: ensuring competent care at the end of life," Geriatric Nursing, vol. 22, no. 6, pp. 288-293, 2001. 


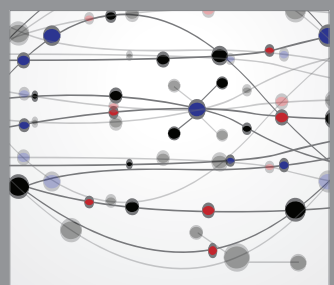

The Scientific World Journal
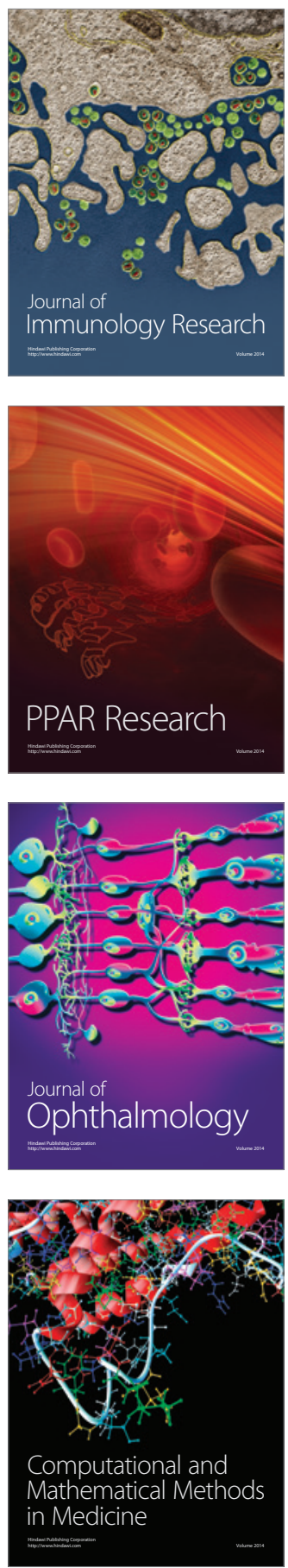

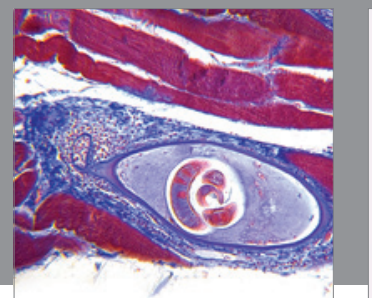

Gastroenterology

Research and Practice
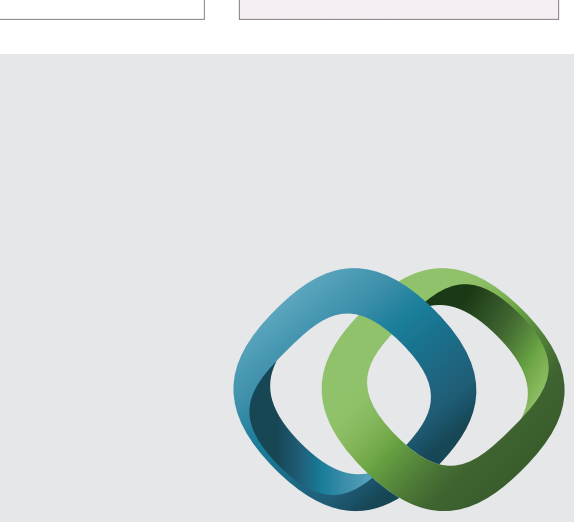

\section{Hindawi}

Submit your manuscripts at

http://www.hindawi.com
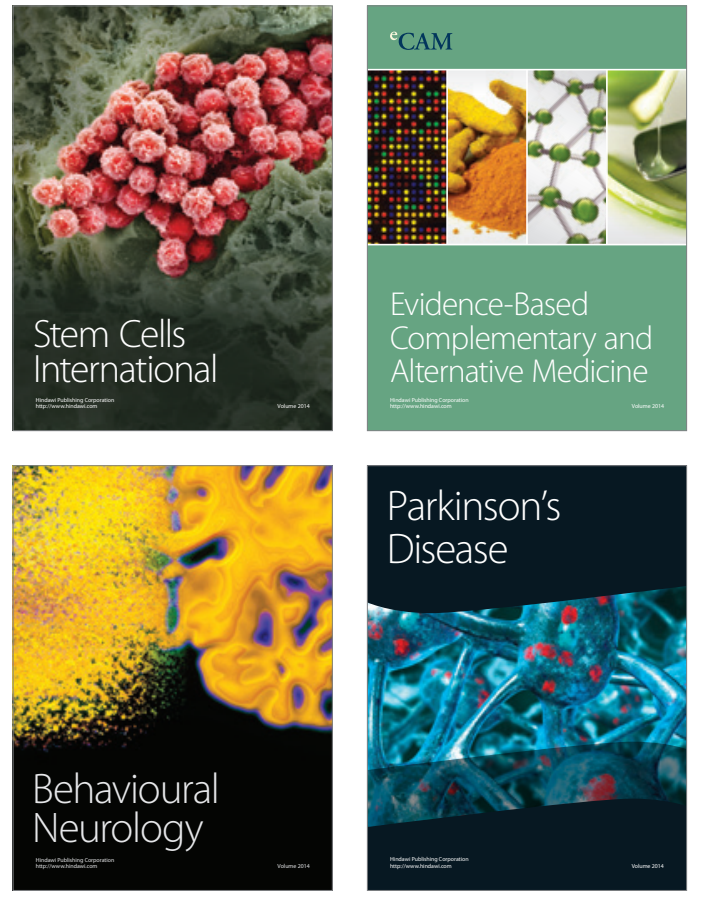
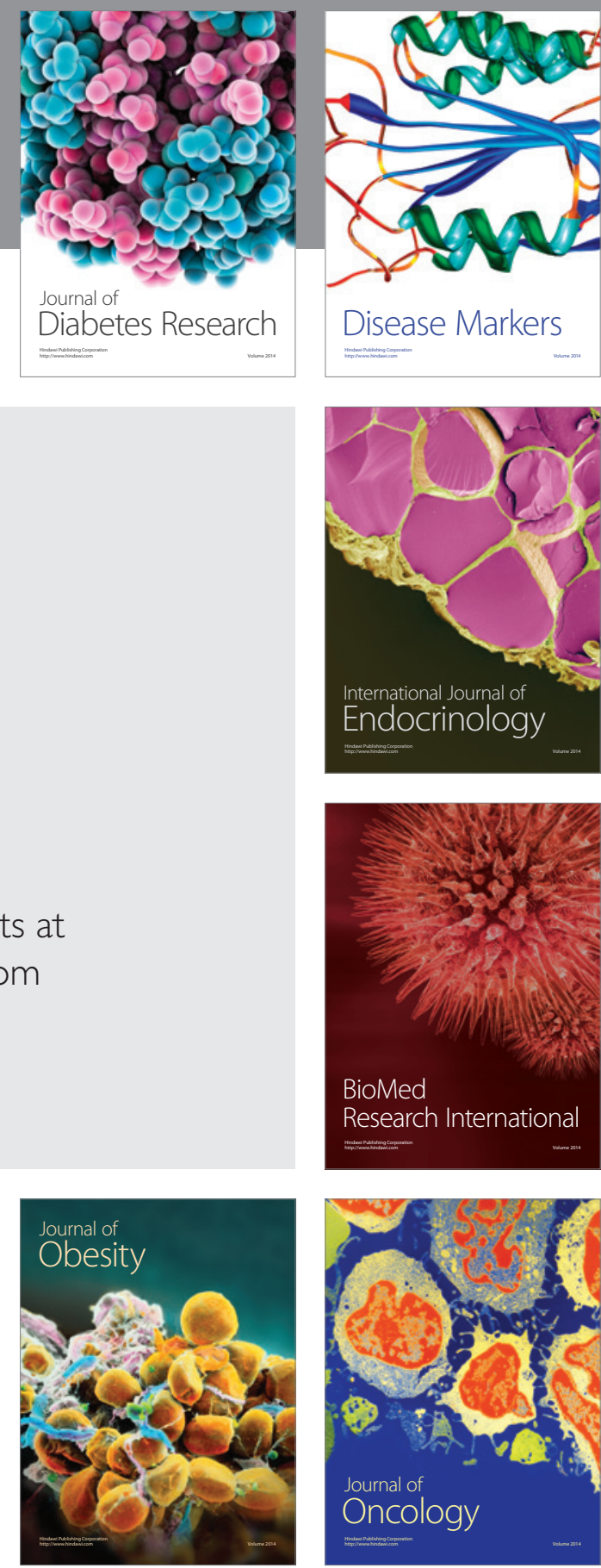

Disease Markers
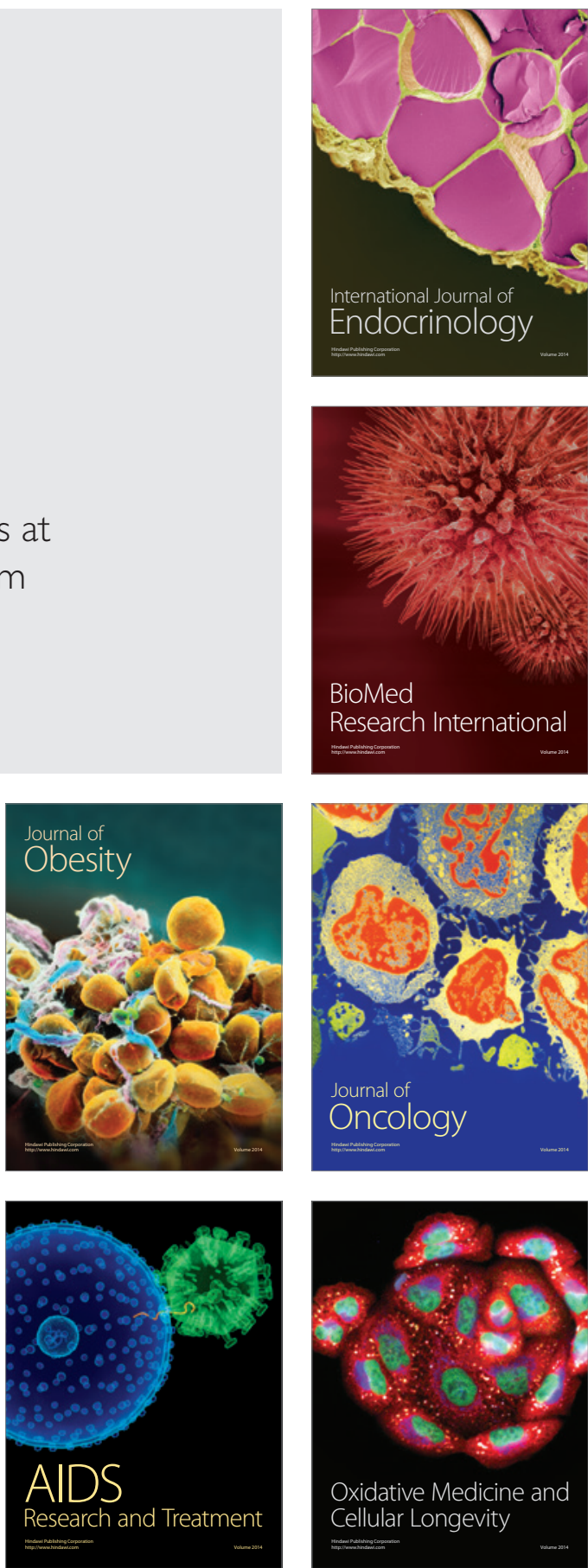